\title{
Dependence of Visitors' Thermal Sensations on Built Environments at an Urban Square
}

\author{
Shahab Kariminia, Sabarinah Sh. Ahmad \\ Faculty of Architecture, Planning and Surveying, \\ Universiti Teknologi MARA, 40450 Shah Alam, Selangor D. E., Malaysia \\ ${ }^{1}$ Corresponding author. Tel.: +6-03-5544-2097; fax: +6-03-5544-2096. \\ sabar643@salam.uitm.edu.my
}

\begin{abstract}
The built environment affects thermal conditions in an urban space, thereby affecting the visitors' thermal comfort. The objective of the study is to determine the effects of landscape attributes on microclimatic conditions and public thermal perceptions at an urban square in temperate and dry region. Simultaneous measurement and questionnaire surveys were conducted in winter and summer in Isfahan, Iran. Thermal stress was found to be higher in summer than in winter. Evaporative cooling by water and providing more air velocities were two useful ameliorating strategies. The visitors were most sensitive to changes of air temperature $\left(T_{a}\right)$ rather than other parameters.
\end{abstract}

Keywords: Thermal comfort; built environment; urban square; microclimates

eISSN 2398-4295 @ 2018. The Authors. Published for AMER ABRA cE-Bs by e-International Publishing House, Ltd., UK. This is an open-access article under the CC BY-NC-ND license (http://creativecommons.org/licenses/bync-nd/4.0/). Peer-review under responsibility of AMER (Association of Malaysian Environment-Behaviour Researchers), ABRA (Association of Behavioural Researchers on Asians) and cE-Bs (Centre for EnvironmentBehaviour Studies), Faculty of Architecture, Planning \& Surveying, Universiti Teknologi MARA, Malaysia.

DOI: http://dx.doi.org/10.21834/ajbes.v3i10.79 


\subsection{Introduction}

Microclimate is a key factor that contributes to the public perception and attractiveness of outdoor settings. Indeed, pedestrians are directly exposed to the outdoor environment and sensitive to the immediate microclimate they experience, which influences their perceptions. It is deteriorated under the recent global warming (Kariminia, Ahmad, \& Hashim, 2012; Kariminia, Ahmad, Hashim, \& Ismail, 2013). Moreover, because of the strong relationship between outdoor and indoor thermal sensations (TSs) (Kariminia, Sh Ahmad, Ibrahim, \& Omar, 2010), the outdoor thermal comfort affects the energy program of buildings. Recent studies have demonstrated that built environment attributes such as surface material (Nikolopoulou \& Steemers, 2003), shading(Nasir, Ahmad, \& Ahmed, 2012), vegetation (Picot, 2004) and water features (Cena \& de Dear, 2001) markedly affect the thermal conditions. Shading helps to reduce the heat stress under the hot conditions. Green areas in cities enhance the climate by filtering sunlight, reducing $T_{a}$ and increasing the humidity in the air.

Several studies have investigated the effects of canyon structure, shading and vegetation on thermal comfort separately. Few studies compared the effects of these modification strategies simultaneously. No previous studies investigated this comparison in urban squares. In this case, Iran addresses specific social and cultural conditions while there is evidence that the public thermal sensation varies with respect to the social, cultural and economic conditions. This study is expected to empirically examine the effect of landscape attributes on microclimatic conditions and thermal comfort at a public square in moderate and dry climate of Iran. The correlation between the visitors' TSs and individual microclimatic parameters were sought as well. Examining the role of thermal adaptations (expectations and perceived control) was another objective of the present work. Two field works including measurement and interview surveys were carried out during two cold and hot seasons.

\subsection{Methodology}

\subsubsection{Data collection}

The field studies were conducted at Naghsh e Jahan Square, located in a historical site. The city of Isfahan is located at $51^{\circ} 41^{\prime} \mathrm{E}$ longitude, $32^{\circ} 37^{\prime} \mathrm{N}$ latitude and altitude of $1590 \mathrm{~m}$ above sea level with hot summers, cold winters and low humidity. The field measurements were performed for a week between 28 December 2009 and 3 January 2010 and another week between 24 and 30 July 2010. Data were acquired from 10:00 to 18:00 at 10-minute intervals. The $\mathrm{Ta}, \mathrm{RH}$, wind speed $\left(\mathrm{W}_{\mathrm{s}}\right)$ and solar radiation $\left(\mathrm{R}_{\mathrm{s}}\right)$ were measured by a portable HOBO data-logging mini weather station. The equipment was placed $1.5 \mathrm{~m}$ above the ground on tripods. The instruments were placed at four pre-selected points in the square at different times to provide data more representative of the different environment of the whole square. The first point was located on an $80 \mathrm{~cm}$ high platform surfaced with high albedo stone, near the entrance porch of Sheikh Lotfollah Mosque at a distance of $1 \mathrm{~m}$ from the façade. The second point was positioned within the vicinity of the bushes. The third point was located 
next to the pool while the fourth point was positioned in the middle of a wide pathway. The locations were labeled as P1-P4, respectively. Structured interviews were conducted simultaneously with the microclimatic measurements. The questionnaires collected the respondents' TS, overall comfort feeling and preferences for microclimatic parameters using 3, 5 and 7-point scales, including the ASHRAE scale (-3: cold, -2: cool, -1: slightly cool, 0: neutral, +1 : slightly warm, +2 : warm, +3 : hot). The next part of the questionnaire inquired about the visitors' reasons for visiting the square. Samples were selected randomly from the population in the square and were interviewed in their natural situations.

\subsubsection{Statistical analyses}

In a correlational research, different groups of people are normally visualized. In a situation when the study aims to compare more than two conditions, ANOVA model is the most applicable. It describes whether three or more group means are the same by testing the null hypothesis that all group means are equal. This study analytically compared the subjects' TSs at the investigated survey campaigns using this method. Furthermore, the correlation between the respondents' perceptions and the individual microclimatic parameters were investigated through regression models.

\subsection{Thermal Behaviours}

The distributions of the visitors' activities throughout the square clarified the visitors' environmental interests and square usage pattern. The largest groups of subjects were involved in three major activities, namely walking, sedentary and standing (Figure $1 \mathrm{a}$ ).

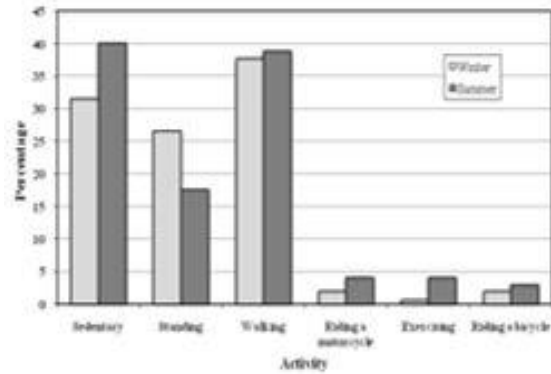

(a)

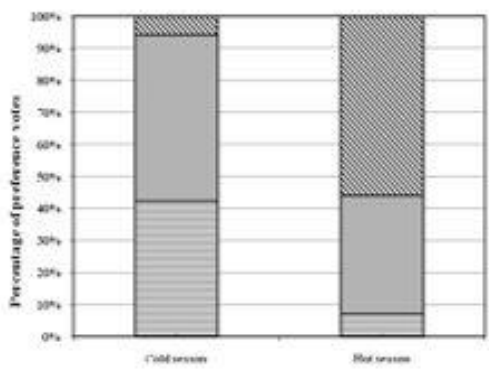

(b)

Figure 1 Percentage of people who felt comfortable in acceptable and unacceptable range versus their reasons for visiting the square (a), Percentage of preference votes for air temperatures in both seasons $(b)$

This addressed the predominant role of urban public space to accommodate the leisure time of the people and to influence their mood and behaviours. Moreover, this square has the historically potential which emphasized this role. Meanwhile, walking comprised the greatest 
group in winter. However, in summer, people preferred to place themselves at certain positions. Indeed, winter weather condition was more tolerable than the hot weather. Exposure to the extreme hot weather encouraged the visitors to stay under the shade or near water.

This study analyses the subjects' responses when they feel comfortable with the $T_{a}$ (subjects who voted one of the three central categories of the scale). Moreover, their preferences were obtained through the questionnaires. Figure 1 (b) compares percentages of the preference votes of this group on the air temperature. The overall preferences are clearly different which confirms the different thermal expectations(Nikolopoulou \& Steemers, 2003) in winter and summer. In fact, people adapted their sensations according to their expectations based on their experience.

Moreover, individuals who realised they can control over a discomfort stimuli, would have wider tolerance for it (Thorsson, Lindberg, Eliasson, \& Holmer, 2007). For instance, when the ability to be in the shade and irradiated places are available, the tolerance for the outdoor conditions is high regardless of where they choose to be. To examine the effect of perceived control on the thermal perception, this study distributed the subjects into four groups according to the reasons for which they attended the square. The percentages of overall comfortable votes of these groups were further compared (Figure 2). The acceptable condition for Isfahan was used from the results of study previously conducted by the authors (Kariminia, Sh Ahmad, \& Ibrahim, 2013) as Physiologically Equivalent Temperature(PET) range between 12.3 and $30.9^{\circ} \mathrm{C}$. However, "being comfortable" was registered based on the responses to the question about overall feeling of being comfortable with the microclimate condition during the interviews.

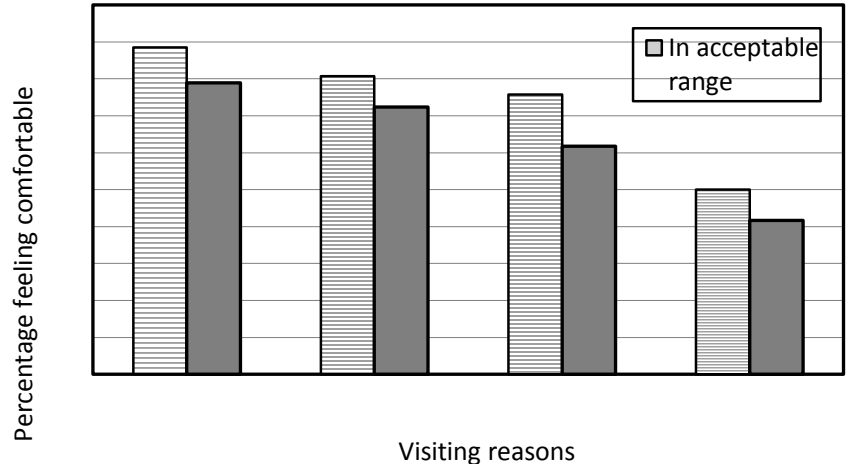

Figure 2 Percentage of people feeling comfortable in acceptable and unacceptable range versus reasons that brought them to the square

The largest percentage of the subjects who were comfortable with the acceptable and unacceptable conditions belonged to the visitors who were resting and sightseeing, followed by those who were shopping or engaging in social activities. Interestingly, the percentage of the members of the first group who were comfortable even while facing the unacceptable 
conditions was more than the other groups who felt comfortable under the acceptable conditions. The people who had to pass through the square had lower tolerance for undesirable thermal conditions compared with those who autonomously attended the square. Subsequently, when visitors had autonomy to choose the nature, location and time of their activity, they were more flexible and tolerable to the thermal stimulants. This clarifies the role of "perceived control" (available choices) in the human TSs as an adaptation process.

\subsection{Role of Built Environment}

In winter, the lowest mean of thermal sensation votes (TSVs) was found at P1 and P3 (Table 1).

Table 1: The descriptive data enquired at the campaigns during two seasons

\section{Thermal sensation}

Winter

Summer

N Std. $\quad 95 \%$ Confidence $\quad$ Std. $95 \%$ Confidence

$\mathrm{N}$ Mean Deviation Interval for Mean N Mean Deviation Interval for Mean

\begin{tabular}{lllllllllll} 
& & \multicolumn{1}{c}{$\begin{array}{c}\text { Lower } \\
\text { Bound }\end{array}$} & $\begin{array}{l}\text { Upper } \\
\text { Bound }\end{array}$ & & & & Lower & Upper \\
& & \multicolumn{1}{c}{ Bound } & Bound \\
\hline P1 Free ambient & 41 & -.76 & .663 & -.97 & -.55 & 60 & .90 & 1.057 & .59 & 1.20 \\
P2 Shaded by building & 40 & -.45 & .959 & -.76 & -.14 & 60 & 1.62 & 1.142 & 1.29 & 1.96 \\
P3 Near vegetation & 43 & -.67 & .944 & -.96 & -.38 & 60 & 1.81 & .982 & 1.53 & 2.10 \\
P4 Near water & 38 & -.45 & .950 & -.76 & -.14 & 60 & .81 & 1.104 & .49 & 1.13 \\
Total & 162 & -.59 & .889 & -.72 & -.45 & & 1.29 & 1.151 & 1.12 & 1.45 \\
\hline
\end{tabular}

However, due to high exposure to the direct solar fluxes, the highest value belonged to P4. By contrast, P2 registered the highest TSs and P2 the lowest. It confirmed the positive effect of the air velocities under hot conditions. Wind was relatively obstructed near the vegetation and associated with higher solar reflections by the vegetation. According to Table 2, the "between groups" data represents the overall experimental effect. Nevertheless, the "within groups" displays details of the unsystematic variation within the data (the variation related to natural individual differences in TSs. Evidently, TSs of the visitors exposed to different environments did not significantly differ in winter ( $P$-value $>0.05$, the cut-off point of 0.05 is applied). Yet, the built environments seemed to be significantly affecting the visitors, perceptions under hot conditions ( $\mathrm{Sig} .<0.01$ ). The last column of the table for each season explains the statistical significance. Indeed, this shows the probability that presented F-ratios would occur if in reality there is no effect of the square's built environment on its visitors' TSs. Therefore, there is a probability of $0.287(28.7 \%$ chance $)$ for the winter whereas the cut-off point of 0.05 is applied. This chance is extremely low as less than $0.1 \%$ ) for summer. In other words, the significant effects of environmental properties (shaded by building, near vegetation and near water) were confirmed on public TSs in summer. In addition, Table 3 compares the mean values of TSVs at the survey places and explains the statistical 
significance of these differences. In winter, the public TSs were close at P4 and P2 on one hand and at P1 and P3 on the other hand. However, the differences were not significantly meaningful. This condition was different in hot weather where P4 and P3 showed higher level of comfort in contrast with $\mathrm{P} 1$ and $\mathrm{P} 2$. This difference in summer was found to be significant.

Table 2: Summary of ANOVA results

\begin{tabular}{|c|c|c|c|c|c|c|c|c|c|c|}
\hline \multicolumn{11}{|c|}{ Thermal sensation } \\
\hline & \multicolumn{5}{|l|}{ Winter } & \multicolumn{5}{|l|}{ Summer } \\
\hline & $\begin{array}{l}\text { Sum of } \\
\text { Squares }\end{array}$ & $\mathrm{df}$ & $\begin{array}{l}\text { Mean } \\
\text { Square }\end{array}$ & $\mathrm{F}$ & Sig. & $\begin{array}{l}\text { Sum of } \\
\text { Squares }\end{array}$ & $\mathrm{df}$ & $\begin{array}{l}\text { Mean } \\
\text { Square }\end{array}$ & $\mathrm{F}$ & Sig. \\
\hline Between Groups & 2.993 & 3 & .998 & 1.268 & .287 & 39.458 & 3 & 13.153 & 10.637 & .000 \\
\hline Within Groups & 124.298 & 158 & .787 & & & 232.458 & 188 & 1.236 & & \\
\hline Total & 127.290 & 161 & & & & 271.917 & 191 & & & \\
\hline
\end{tabular}

Table 3: Multiple comparisons between TSs at the survey campaigns

\begin{tabular}{llllll}
\hline \multirow{2}{*}{ Environment } & & \multicolumn{3}{l}{ Winter } & \multicolumn{3}{l}{ Summer } \\
\cline { 3 - 6 } & & $\begin{array}{l}\text { Mean } \\
\text { Difference }\end{array}$ & Sig. & Difference & Sig. \\
\hline Free ambient & Building shade & .309 & 544 & $-.771^{*}$ & .005 \\
& Vegetation & .003 & 1.000 & $-.958^{*}$ & .000 \\
& Water & .227 & .821 & .062 & .993 \\
\hline
\end{tabular}

\subsection{Effects of Microclimate}

Sets of multi regression tests looked for the dependency of the thermal sensation votes (TSVs) on $T_{a}, R_{s}, W_{s}$ and $\mathrm{RH}$ during the two field experiments. Table 4 reports a summary of data set on the mean and standard deviation of each variable. The average values of the TSVs are -0.59 and 1.29 in winter and summer, respectively. The Pearson's correlation coefficient between every pair of variables is demonstrated in the correlation matrix (Table 5). This outcome is highly useful for getting a rough idea of the relationships between the dependent and independent variables. The TSVs are significantly correlated in summer but did not show a large correlation with the microclimate variables in the winter. The TSVs in winter are shown to be significantly correlated with $T_{a}, R_{s}$ and $R H(p<0.05)$ albeit ignoring the corresponding correlation with the $\mathrm{W}_{\mathrm{s}}$.

Table 4: Data summary in terms of the variables

\begin{tabular}{lllll}
\hline & \multicolumn{3}{c}{ Winter } & \multicolumn{3}{l}{ Summer } \\
\cline { 2 - 5 } & Mean & Std. Deviation & Mean & Std. Deviation \\
\hline Thermal Sensation & -.5926 & .86732 & 1.29 & 1.177 \\
Ta & 10.7600 & 1.94251 & 32.3722 & 3.51089 \\
Rs & 267.5259 & 197.25996 & 722.0858 & 276.14594 \\
Ws & .9725 & .53303 & .9483 & .64750 \\
RH & 47.5759 & 9.09131 & 17.2325 & 4.64114 \\
\hline
\end{tabular}


Table 5: Correlation between thermal sensation (TS) and microclimatic variables

\begin{tabular}{|c|c|c|c|c|c|c|}
\hline \multirow[b]{3}{*}{ Constant } & \multicolumn{3}{|l|}{ Winter } & \multicolumn{3}{|l|}{ Summer } \\
\hline & $\begin{array}{l}\text { Pearson } \\
\text { Correlation }\end{array}$ & $\begin{array}{l}\text { Sig. } \\
\text { (1-tailed) }\end{array}$ & B (coefficient) & $\begin{array}{l}\text { Pearson } \\
\text { Correlation }\end{array}$ & $\begin{array}{l}\text { Sig. } \\
\text { (1-tailed) }\end{array}$ & B (coefficient) \\
\hline & & & -1.341 & & & -1.647 \\
\hline $\mathrm{Ta}$ & 0.326 & .001 & 0.134 & 0.312 & .000 & 0.056 \\
\hline Rs & 0.188 & .003 & 0.001 & 0.478 & .000 & 0.004 \\
\hline Ws & 0.084 & .216 & -.069 & 0.056 & .025 & -0.479 \\
\hline $\mathrm{RH}$ & -0.185 & .000 & 0.001 & 0.023 & .000 & -0.057 \\
\hline
\end{tabular}

According to Table 6, the multiple correlation coefficient between the independent and dependent variables is moderate (0.47) for the winter data, nevertheless, for summer, it is robust (nearly 0.9 ). The $\mathrm{R}^{2}$ represent the amount of variability in the TSVs, which is accounted for by the microclimatic parameters. The adjusted $R^{2}$ gives an idea of how well the model generalizes and is best when is close to the $\mathrm{R}^{2}$. The discrepancy is smaller in winter as 0.216 $-0.157=0.06$ i.e. $6 \%$. This shrinkage explains that if the model is derived from the entire population rather than a sample, it would account for roughly $6 \%$ less variance in the outcome. The changes in the amount of variances that can be explained rises to F-ratios are significant (less than 0.05 ) for the two seasons.

\begin{tabular}{llllllllll} 
& \multicolumn{1}{c}{ Table 6: Model summary } \\
\cline { 2 - 10 } & Winter & \multicolumn{10}{c}{ Summer } \\
\hline $\mathrm{R}$ & $\mathrm{R}^{2}$ & $\mathrm{R}^{2}$ & Cdjusted & $\mathrm{F}$ & Sig. $\mathrm{F}$ & & Adjusted & $\mathrm{F}$ & Sig. $\mathrm{F}$ \\
\hline 0.465 & 0.216 & 0.157 & 3.646 & 0.000 & 0.880 & 0.774 & 0.562 & 3.653 & 0.007 \\
\hline
\end{tabular}

So far, the results demonstrated the ability of derived regression model to predict the outcome accurately. Yet, the coefficient values in Table 5 demonstrate the individual contribution of the variables to the model. Thus, the regression models rely on the following equations (1-2):

\section{$0.001 \mathrm{RH}$}

$$
\text { TSVs-Win }=-1.341+0.134 \mathrm{Ta}+0.001 \mathrm{Rs}-0.069 \mathrm{Ws}+
$$

\section{$0.057 \mathrm{RH}$}

$$
\text { TSVs-Sum }=-1.647+0.056 \mathrm{Ta}+0.004 \mathrm{Rs}-0.479 \mathrm{Ws}-
$$

Meanwhile, in winter, TSVs are clearly found to have negative relationship with $\mathrm{W}_{\mathrm{s}}$. According to the above equation, if the $T_{a}$ increases by 1 degree in winter, the TSV value increases 0.134 unit of the scale. That is only 0.001 scale increase for $1 \mathrm{w} / \mathrm{m}^{2}$ increase of solar radiation and so on. If all values of the microclimatic parameters equal zero, the TSVs will be -1.341 . 
Kariminia, S., \& Sh. Ahmad, S. / Asian Journal of Behavioural Studies (AjBeS), 3(10) Mar / Apr 2018 (p.43-52)
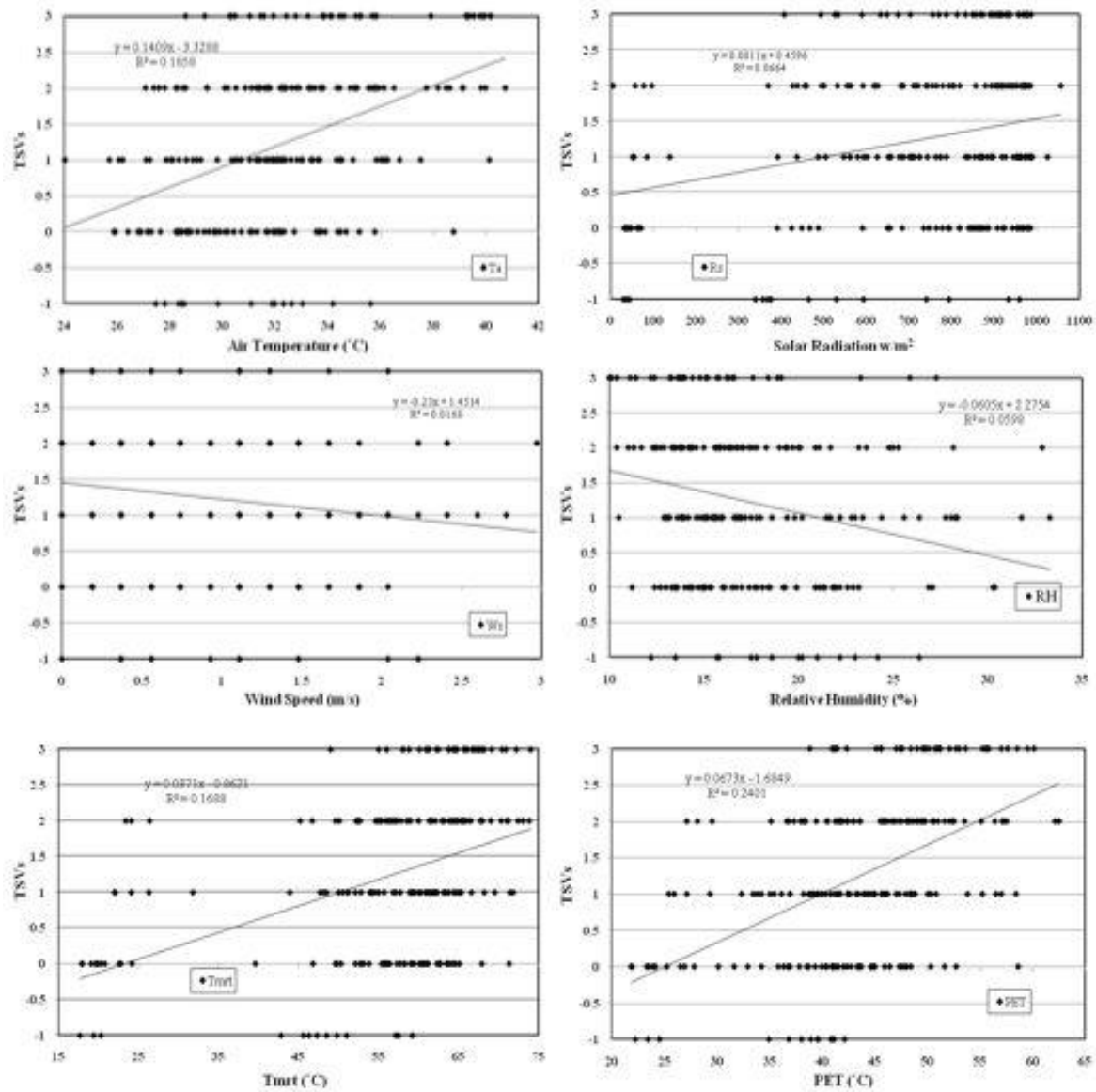

Figure 3 Relationship of thermal sensation votes (TSVs) with the microclimatic factors

However, in summer, if the microclimatic parameters equal to zero, the TVSs were lower at -1.647. It confirms the influences of thermal adaptations (experience and expectations) when people expect the summer conditions to be hotter. Thus, they feel much cooler in summer rather than winter under the same cold weather (replacing zero to the variables registers a cold condition).

Additionally, Figure 3 represents relationship of TSVs with microclimatic variables in summer as the more thermally stressful season. TSVs correlate moderately with Ta and PET while the relationship is poor for the other variables. The correlation is negative for $W_{s}$ and $\mathrm{RH}$ because TSVs decreases with the increase of these two factors. The slope of the 
regression line is the highest for $T_{a}$, which indicates the visitors are most sensitive to the changes in the Ta rather than other microclimatic factors.

\subsection{Conclusion}

This study investigated the effects of built environment on the visitors' thermal perceptions of an urban square in Isfahan, Iran. The outdoor thermal environments were measured during two extreme cold and hot conditions. The visitors' sensations and preferences were simultaneously enquired through structured interviews. The obtained TSVs were statistically analyzed in terms of the environment where the respondents were exposed to. Microclimatic measures fluctuated widely during the year and were found to be varying concerning the environment. People were more comfortable with the thermal conditions in winter. The square was observed to have dominant role in accommodating the city residents and improve their mood and behaviours. Expectations influences individuals' TSs as it contributes to adapting to the thermal conditions. People who autonomously frequented the square had higher tolerance to the thermal conditions as the function of perceived control. The visitors' TSs in summer significantly varied with the environmental attributes to which they exposed to at the square including shading, water or vegetation. Yet, no significant effect was found for the cold conditions. Individuals who were under higher radiation fluxes at the free ambient area and those near the fountain respectively in winter and summer were found to feel more comfortable with the thermal conditions. Evaporative cooling effects of water and air velocity are the two useful strategies to ameliorate thermal stress under the hot conditions. All the tested microclimatic parameters i.e. $T_{a}, R_{s}, W_{s}$ and $\mathrm{RH}$ correlated with public TSVs under two extreme conditions except $W_{s}$ in winter. People are the most sensitive to the changes of $T_{a}$ in summer compared with the other parameters. The findings are beneficial for those considering thermal comfort in urban planning and landscape design in moderate and dry climate with similar conditions to Isfahan. Further studies can seek the effect of other environmental properties on outdoor thermal comfort.

\section{Acknowledgement}

The authors would like to acknowledge Research Management Institute (RMI), UniversitiTeknologi MARA for funding this research.

\section{References}

Cena, K., \& de Dear, R. (2001). Thermal comfort and behavioural strategies in office buildings located in a hot-arid climate. Journal of Thermal Biology, 26(4), 409-414.

Kariminia, S., Sh Ahmad, S., \& Ibrahim, N. (2013). Landscape Attributes, Microclimate and Thermal Comfort of an Urban Square in Moderate and Dry Climate. Advanced Materials Research, 610, 3780-3784. 
Kariminia, S., \& Sh. Ahmad, S. / Asian Journal of Behavioural Studies (AjBeS), 3(10) Mar / Apr 2018 (p.43-52)

Kariminia, S., Sh Ahmad, S., Ibrahim, N., \& Omar, M. (2010). Outdoor thermal comfort of two public squares in temperate and dry region of Esfahan, Iran. Paper presented at the 2010 International Conference on Science and Social Research (CSSR), .

Kariminia, Shahab, Ahmad, Sabarinah Sh, \& Hashim, Rugayah. (2012). Assessment of Antarctic Tourism Waste Disposal and Management Strategies towards a Sustainable Ecosystem. Procedia - Social and Behavioral Sciences, 68(0), 723-734.

Kariminia, Shahab, Ahmad, Sabarinah Sh, Hashim, Rugayah, \& Ismail, Zulhabri. (2013). Environmental Consequences of Antarctic Tourism from a Global Perspective. Procedia - Social and Behavioral Sciences, 105(0), 781-791.

Nasir, Rabiatul Adawiyah, Ahmad, Sabarinah Sh, \& Ahmed, Azni Zain. (2012). Psychological Adaptation of Outdoor Thermal Comfort in Shaded Green Spaces in Malaysia. Procedia - Social and Behavioral Sciences, 68(0), 865-878. doi: http://dx.doi.org/10.1016/j.sbspro.2012.12.273

Nikolopoulou, M., \& Steemers, K. (2003). Thermal comfort and psychological adaptation as a guide for designing urban spaces. Energy and Buildings, 35(1), 95-101.

Picot, X. (2004). Thermal comfort in urban spaces: impact of vegetation growth:: Case study: Piazza della Scienza, Milan, Italy. Energy and Buildings, 36(4), 329-334.

Thorsson, S., Lindberg, F., Eliasson, I., \& Holmer, B. (2007). Different methods for estimating the mean radiant temperature in an outdoor urban setting. International Journal of Climatology, 27(14), 1983-1993. 